\title{
Changes in work behavior during pregnancy in rural Anhui, China from 2001-03 to 2009: a population based cross-sectional study
}

\author{
Subas Neupane ${ }^{1^{*}}$, Bright I. Nwaru ${ }^{1,2}$, Zhuochun $\mathrm{Wu}^{3}$ and Elina Hemminki ${ }^{4}$
}

\begin{abstract}
Background: In low- and middle-income countries, many women continue working later into pregnancy. In our recent study on some areas in rural China, most women stopped working already during the first trimester ( $\leq 3$ months) of pregnancy. In this paper we aimed to explore whether stopping work during early pregnancy has changed over an 8 year period (between 2001-03 and 2009); we also studied whether the reasons for stopping work early were the same in the two time periods.

Methods: A population-based cross-sectional survey with a representative sample of new mothers was carried out in one rural county in Anhui Province in 2001-03 ( $N=1479$ respondents) and in two other rural counties in 2009 ( $N=1574$ respondents). Both surveys were used to evaluate prenatal care interventions not related to work behavior. The surveys targeted all women who had recently given birth. Multilevel logistic regression analysis was used to examine the determinants of work behavior in the two time periods.

Results: There was a big change in the working behavior between the two survey years: in the period 2001-03 $6 \%$ and in 2009, $53 \%$ of pregnant women stopped working at $\leq 3$ months (percentage change $839,95 \% \mathrm{Cl}-15$. 90 to 1694.49). In 2001-03, $30 \%$ and in 2009, $23 \%$ of pregnant women worked the same as before pregnancy (percentage change $-22.30,95 \% \mathrm{Cl}-90.28$ to 45.68 ). In both time periods women with two children were less likely to stop work at $\leq 3$ months of pregnancy. Non-farmers were more likely in 2001-03 but less likely in 2009 to stop work at $\leq 3$ months of pregnancy. Women with medium township-level income were more likely to maintain the same level of work as before pregnancy in 2001-03, while in 2009 women with high township-level income were less likely to work the same.
\end{abstract}

Conclusion: Stopping work very early during pregnancy appeared to have become very common from 2001-3 to 2009 in rural Anhui, China and was not explained by women's background characteristics.

Keywords: Pregnancy, Working patterns, Maternal work, Rural China

\footnotetext{
* Correspondence: subas.neupane@uta.fi

'School of Health Sciences, Fl-33014 UNiversity of Tampere, Tampere, Finland

Full list of author information is available at the end of the article
} 


\section{Background}

Work during pregnancy is not in and of itself a risk, even though some work can be a threat to maternal health and fetal outcomes [1-3]. Maternal work during pregnancy, especially high work-related exertion, physical work demands, long working hours, shift work and occupational stress are also still considered as the most prevalent risk factors of negative pregnancy outcome [4-10].

Although several studies have been published on women's work and pregnancy outcomes, only few of these have focused on women's working behavior during pregnancy in low- and middle-income countries [11-13]. In China, in the late 1980s and early 1990s, paid work involved full-time work of $8 \mathrm{~h}$ a day, six days a week [14]. However, agricultural fieldwork was more flexible than salaried work, but for most women, the work was equally or more demanding. Nowadays the world of work has changed in rural China; especially women's work during pregnancy has become more flexible, including shorter working hours, additional breaks, or reduction in the work required.

In a survey in 2009 in three rural provinces in China [13], we found that most women in two of the provinces stopped work already during the first trimester ( $\leq 3$ months) of pregnancy. In this paper, using the opportunity provided by a survey undertaken in an earlier period (2001-03) in one of these provinces, we wanted to find out whether stopping work early in pregnancy was an old or a new phenomenon. We were also interested in ascertaining the determinants of work behavior and whether these were the same in the two time periods.

\section{Methods}

\section{Study design and subjects}

This study is based on two population-based surveys conducted in 2001-03 and 2009 in rural areas of Anhui Province, China. The surveys have been described in detail elsewhere $[15,16]$ and only the key features are given here. The first study was conducted as a prenatal care Knowledge, Attitude and Practice (KAP) survey involving 20 rural townships in one county in 2001-2003. The KAP survey was used to evaluate a prenatal care intervention carried out in 1999 [15, 17]. In 2001, interviews were conducted in $10 \%$ of the villages, in 2002 in $20 \%$ and in 2003 in $70 \%$. Participants in the survey were women who had given birth during the preceding 12 months and who had been identified from a list provided by the family planning system. At the time, family planning system kept records of all life events, including pregnancies and births. Overall, 1479 women (97\% response rate) completed the survey; $3 \%$ of the sample was missing due to refusal, being absent, or for other reasons. Women whose children had died were not interviewed. The non-respondents were few because only few were working out of town or refused to participate in the interview. Proxy respondents (a husband or another family member) responded if the mother was not at home. Health workers from the townships trained by a local researcher employed by Fudan University carried out the survey.

The second survey was conducted in 2008-2009 as a tool to evaluate prenatal care interventions implemented in rural areas of three provinces (Anhui, Chongquing and Shaan'xi) [16-18]. Thirty townships in two counties (not the same as in 2001-2003) of Anhui Province were selected for the intervention or to serve as controls. Participants in the survey were the women who had given birth in the study counties during the year 2008 $[18,19]$. Women to be interviewed were identified through various methods: through doctors and family planning workers, the birth registers of township hospitals and snowballing. A letter of invitation explaining the purpose of the study was given or sent to the women [18]. Altogether 1576 women were interviewed (estimated response rate $73 \%)$. Proxy respondents i.e., relatives of the women (7\% of the study population) [20] were used if the respondents were not available at home in the second attempt. Non-participants were working out of town, had an unclear address, were not at home (with no proxy respondents available), or had transportation problems. Trained interviewers conducted the interview.

The interview instrument was a 60-item structured questionnaire in the first survey and a 79-item questionnaire in the second survey. In both surveys, data on mothers' demographics, work behavior, the content of prenatal care and other information on maternal health care and health outcomes were collected. The first survey instrument was used as a model for the second instrument. The questions on work behavior were identical in the two surveys and the other questions used in this paper were comparable. Questions on income varied (see below), but a comparable classification was used. The questionnaires in both surveys were developed in English, translated into Chinese, and checked against the English version by a bilingual researcher.

\section{Variables used}

The socio-demographic covariates studied in this study were maternal age ( $\leq 24$ years, $25-29$ years and $\geq 30$ years), mother's income during the first study in 2001-03 (low = $<209$ \$, medium $=209-229$ \$, high $=>229$ \$ (1 US dollar was equivalent of $8.29 \mathrm{CNY}$ at the time of the study in 2001), while in 2009 total family income was collected instead of mother's own income $(<2174$ \$, 2174-4348 \$, $>4348$ \$: 1 US dollar was equivalent of $6.9 \mathrm{CNY}$ at the time of the study in 2009), number of children at the time of interview (one, two, three), mother's occupation (farmer, non-farmer). Township-level income was calculated by aggregating mothers' incomes in 2001-03 and 
aggregating family total incomes in 2009 and dividing them into three categories (low, medium, and high) based on their tertile values. Prenatal visits during the pregnancy included visits to the doctor/midwife at the township hospital; their visits to her; and mothers' visits to other health practitioners because of pregnancy. The time of starting prenatal care was categorized into $\leq 3$ months, 4-5 months, 6 months, 7-9 months' gestation, and no care.

\section{Work during pregnancy}

Work outside home during pregnancy was measured with the question: 'which of the following statements best describes your working outside home (farming work in the fields or in paid work) during pregnancy?' with the following responses (a) I worked the same as before pregnancy; (b) I worked less heavily than before pregnancy from ... months; and (c) I stopped working completely from ... months. For analyses, we created the following categories; worked the same, stopped work at $\leq 3$ months, stopped work $>3$ months, decreased work at $\leq 3$ months, decreased work $>3$ months. If a woman had chosen many alternatives, she was grouped in the order given above [6]. Thus, the option 'stopped work' may also include reducing work in another stage of pregnancy.

\section{Statistical analysis}

Descriptive statistics were calculated and presented as numbers and percentages. The percentage changes in work behavior and their $95 \%$ confidence intervals (CI) were calculated. The statistical significances of the differences in the proportions were tested using Pearson's chisquare test. To calculate the associations between maternal characteristics and working behavior, multilevel logistic regression was used. A multilevel modeling procedure was employed [21] as the structure of the data used for analyses was individuals nested within villages and villages nested in townships. In the model, all individual level characteristics (maternal age, time of start of prenatal care, parity, mother's occupation, mother's income/family total income) and township level income were simultaneously adjusted. The random part of the models was estimated by computing the variance of the township-level variations and their accompanying standard errors. All analyses were performed using generalized linear latent and mixed models in stata 11'gllamm', (Stata Corp LP, College Station, TX).

\section{Results}

Table 1 shows the background characteristics of mothers in 2001-03 and 2009. The age distributions were relatively similar. The proportion of women starting prenatal care visits early increased and the proportion of mothers having three children or more decreased over time. In
2001-03 fewer women (14 \%) had a non-farming occupation than in 2009 (27\%). The income level was much higher in 2009 than in 2001-03.

The working behaviors during pregnancy were very different in the two time periods (Table 2): In 2001-03 only $6 \%$ of women had stopped working in early pregnancy ( $\leq 3$ months), while over half had done so in 2009 (\% change 839, $95 \%$ CI -15.90 to 1694.49$)$. On the other hand, the proportion of women who had reduced their workload was smaller in 2009 than in 2001-03 (\% change for decreased work $\leq 3$ months, $-69.495 \% \mathrm{CI}-97.6$ to -41.2$)$. The proportion of women working the same as before pregnancy was smaller in 2009 than in 2001-03 (\% change -22.3 $95 \%$ CI -90.3 to 45.7$)$.

Table 3 presents the adjusted associations between the women's socio-demographic characteristics and work behavior in 2001-03 and 2009. Women's age had no statistically significant association with stopping work early in pregnancy in either survey. Women having their second child were less likely than women having their first child to stop working early in pregnancy in both surveys. Women's income, family total income, and township-level income made no difference to stopping work early in the same way in the two time periods. In 2001-03, farmers were less likely and in 2009 more likely to stop working early. In 2001-03, but not in 2009, women starting prenatal care very late (at 7 months of pregnancy or later) were more likely to stop working early.

Older women were significantly more likely than the youngest women to work the same during pregnancy in 2001-03 but not in 2009 (Table 3). Women with two children were more likely to work the same during pregnancy in both surveys; however, the association was significant only in 2009. Women's income and family total income were not associated with working the same during pregnancy, but those with medium income were more likely to work the same in 2001-03. Medium townshiplevel income was strongly associated with higher likelihood of working the same during pregnancy in 2001-03, but having high township-level income was related to lesser likelihood of working the same in 2009. Nonfarmers were significantly more likely to work the same during pregnancy in 2009 but less likely in 2001-03. Women seeking no prenatal care were significantly more likely to work the same during pregnancy than those who had some prenatal visit in 2001-03 but not in 2009 .

\section{Discussion}

This study showed that in rural China in 2001-03 only $6 \%$ of pregnant women stopped working at or before 3 months of pregnancy and that in 2009 more than half of the women stopped working; such findings have not been reported from other settings. The difference between the two time periods suggests that stopping work in early 
Table 1 Background characteristics of women participating in the surveys in 2001-03 and 2009 in Anhui Province, China

\begin{tabular}{|c|c|c|c|c|}
\hline \multirow[t]{2}{*}{ Characteristics } & \multicolumn{2}{|c|}{$\begin{array}{l}2001-03 \\
(N=1479)\end{array}$} & \multicolumn{2}{|c|}{$\begin{array}{l}2009 \\
(N=1574)\end{array}$} \\
\hline & $\overline{\mathrm{N}}$ & $\%$ & $\mathrm{~N}$ & $\%$ \\
\hline \multicolumn{5}{|l|}{$\overline{\text { Age }}$} \\
\hline$\leq 24$ years & 482 & 32.6 & 592 & 37.6 \\
\hline $25-29$ years & 573 & 38.7 & 567 & 36.1 \\
\hline$\geq 30$ year & 374 & 25.3 & 415 & 26.3 \\
\hline No information & 50 & 3.4 & - & - \\
\hline \multicolumn{5}{|l|}{ Time of starting prenatal care } \\
\hline 3 months or less & 618 & 41.8 & 1005 & 63.5 \\
\hline 4-5 months & 459 & 31.0 & 391 & 14.8 \\
\hline 6 months & 177 & 12.0 & 84 & 5.3 \\
\hline 7-9 months & 90 & 6.1 & 47 & 3.0 \\
\hline No care ${ }^{a}$ & 135 & 9.1 & 47 & 3.0 \\
\hline \multicolumn{5}{|l|}{ Number of children } \\
\hline 1 & 905 & 61.2 & 1078 & 68.5 \\
\hline 2 & 338 & 22.9 & 487 & 30.9 \\
\hline 3 & 236 & 16.0 & 9 & 0.6 \\
\hline \multicolumn{5}{|l|}{ Occupation } \\
\hline Farmer & 1220 & 82.5 & 1147 & 72.9 \\
\hline Non-farmer & 209 & 14.1 & 427 & 27.1 \\
\hline No information & 50 & 3.4 & - & - \\
\hline Women's income ${ }^{\mathrm{b}}$ (Mean, SD) & $\begin{array}{l}217.0 \\
(212.3)\end{array}$ & - & & \\
\hline $\begin{array}{l}\text { Family total income }{ }^{c} \text { (Mean, } \\
\text { SD) }\end{array}$ & - & $3521.2(3591.6)$ & & \\
\hline
\end{tabular}

pregnancy is a new phenomenon. The proportion of women who maintain the same level of work as before pregnancy declined somewhat during this period.

In developed countries, pregnant women are often advised to reduce or stop strenuous or dangerous work in order to protect the well-being of the mother and the fetus [22, 23]. Women are not usually advised to stop working completely if they are healthy. Pregnant women doing light work may continue to the last trimester [22].

In our study, the pattern of working behavior appeared not to be substantially explained by women's sociodemographic characteristics, and only some of the background factors were related to working behavior: maternal age and income were not related to stopping work early; starting prenatal care late increased the likelihood of stopping work early in 2001-3, but not in 2009; being a farmer was related in an opposite way in the two surveys. Women with two or more children were less likely to stop work early. We do not know the reason for the finding, but the following factors may have contributed: having many children may have led to an economic necessity to work, a second-time mother could have been less worried or felt better during pregnancy than a first-time mother. A fourth potential explanation is that the second child may have been unauthorized [24] causing social and economic pressure to work.

What could have caused the large increase in the number of women stopping working in the 2000s? Below we briefly present six potential factors which could have contributed to it and give our subjective estimations of how likely these explanations are: changes in health status, strenuousness of work, pregnancy culture, pregnancy care practices, population policy and income.

Pregnancy produces health changes [25]. We did not have information on the women's health, but it is unlikely that the average health of pregnant women had declined so radically in such a short time. However, as the study areas were different in the two time periods, health status as a reason cannot be totally excluded.

Most of the women (more than $80 \%$ in 2001-3 and more than $70 \%$ in 2009) were engaged in farming. Farmers were less likely to stop working early in 2001-03 and more likely in 2009. It is not likely that farming had become heavier during that time. However, we do not have information on the division of labor between the

Table 2 Distribution (\%) of women's work behavior during pregnancy in 2001-03 and 2009 in rural areas in Anhui Province of China

\begin{tabular}{lccll}
\hline Working patterns during pregnancy & $2001-03$ & 2009 & $\begin{array}{l}P \text {-value } \\
(N=1479)\end{array}$ & $\begin{array}{l}\text { Percentage change in work behavior } \\
\text { between 2001-03 and 2009 } \\
\% \text { change }(95 \% \text { Cl) }\end{array}$ \\
\hline Worked the same & $\%$ & 23.3 & $<0.001$ & $-22.3(-90.3$ to 45.7$)$ \\
Stopped work $\leq 3$ months & 30.0 & 52.6 & $<0.001$ & $839.3(-15.9$ to 1694.5$)$ \\
Stopped work $>3$ months & 5.6 & 11.5 & $<0.001$ & $144.7(-82.5$ to 371.9) \\
Decreased work $\leq 3$ months & 4.7 & 10.0 & $<0.001$ & $-69.4(-97.6$ to -41.2$)$ \\
Decreased work $>3$ months & 32.7 & 2.4 & $<0.001$ & $-90.9(-99.1$ to -82.8$)$ \\
Missing & 26.4 & - & &
\end{tabular}

${ }^{\mathrm{a}} P$-value for the differences in the proportion of work behavior between two time periods 
Table 3 Odds ratios (OR) and $95 \%$ confidence intervals (CI) of determinants for stopping working early in pregnancy and for working the same as before pregnancy in rural areas in Anhui Province, China in 2001-03 and 2009

\begin{tabular}{|c|c|c|c|c|}
\hline \multirow[t]{3}{*}{ Variables } & \multicolumn{2}{|c|}{$\begin{array}{l}\text { Stopped work } \leq 3 \text { months }^{a} \\
\text { aOR }(95 \% \text { Cl) }\end{array}$} & \multicolumn{2}{|c|}{$\begin{array}{l}\text { Worked the same during pregnancy } \\
\text { aOR }(95 \% \mathrm{Cl})^{d}\end{array}$} \\
\hline & $2001-03$ & 2009 & 2001-03 & 2009 \\
\hline & $N=83$ & $N=829$ & $N=444$ & $N=367$ \\
\hline \multicolumn{5}{|l|}{ Age } \\
\hline$\leq 24$ years & 1.0 & 1.0 & 1.0 & 1.0 \\
\hline $25-29$ years & $1.10(0.66-1.85)$ & $0.95(0.74-1.23)$ & $1.70(1.25-2.30)$ & $1.06(0.77-1.46)$ \\
\hline$\geq 30$ year & $0.54(0.22-1.30)$ & $0.72(0.50-1.05)$ & $1.71(1.16-2.52)$ & $1.30(0.83-2.03)$ \\
\hline \multicolumn{5}{|l|}{ Time of starting prenatal care } \\
\hline 3 months or less & 1.0 & 1.0 & 1.0 & 1.0 \\
\hline $4-5$ months & $1.62(0.92-2.84)$ & $0.88(0.68-1.12)$ & $1.13(0.82-1.56)$ & $0.98(0.72-1.33)$ \\
\hline 6 months & $1.07(0.46-2.45)$ & $0.54(0.28-1.01)$ & $1.33(0.87-2.05)$ & $1.75(0.88-3.48)$ \\
\hline 7-9 months & $2.94(1.32-6.54)$ & $1.00(0.63-1.60)$ & $1.43(0.83-2.46)$ & $0.61(0.32-1.16)$ \\
\hline No care & $1.38(0.57-3.33)$ & $0.89(0.48-1.65)$ & $2.83(1.82-4.38)$ & $1.29(0.65-2.55)$ \\
\hline \multicolumn{5}{|l|}{ No. of children } \\
\hline 1 & 1.0 & 1.0 & 1.0 & 1.0 \\
\hline 2 & $0.44(0.20-0.97)$ & $0.62(0.45-0.85)$ & $1.31(0.92-1.85)$ & $1.48(1.02-2.15)$ \\
\hline 3 & $0.37(0.16-0.85)$ & c & $1.06(0.72-1.56)$ & c \\
\hline \multicolumn{5}{|l|}{ Women's occupation } \\
\hline Farmer & 1.0 & 1.0 & 1.0 & 1.0 \\
\hline Non-farmer & $2.45(1.37-4.39)$ & $0.72(0.56-0.91)$ & $0.67(0.44-1.02)$ & $1.79(1.35-2.37)$ \\
\hline \multicolumn{5}{|l|}{ Women's Income } \\
\hline Low (<209\$) & 1.0 & & 1.0 & \\
\hline Medium (209-229\$) & $1.30(0.67-2.52)$ & NA & $0.49(0.22-1.10)$ & NA \\
\hline High (>229\$) & $0.73(0.35-1.49)$ & NA & $1.66(0.70-3.94)$ & NA \\
\hline \multicolumn{5}{|l|}{ Family Total Income } \\
\hline Low (<2174\$) & & 1.0 & & 1.0 \\
\hline Medium (2174-4348\$) & NA & $0.99(0.77-1.29)$ & NA & $0.84(0.62-1.15)$ \\
\hline High (>4348\$) & NA & $1.12(0.87-1.45)$ & NA & $0.78(0.57-1.07)$ \\
\hline \multicolumn{5}{|l|}{ Township-level Income } \\
\hline Low & 1.0 & 1.0 & 1.0 & 1.0 \\
\hline Medium & $0.90(0.43-1.88)$ & $0.81(0.55-1.19)$ & $3.67(1.55-8.68)$ & $1.43(0.77-2.65)$ \\
\hline High & $0.79(0.39-1.60)$ & $1.28(0.85-1.91)$ & $1.55(0.65-3.68)$ & $0.49(0.25-0.98)$ \\
\hline \multicolumn{5}{|l|}{ Model statistics } \\
\hline Log likelihood & -287.431 & -1048.919 & -736.991 & -783.90 \\
\hline Township level variance (SE ${ }^{\mathrm{b}}$ ) & $0.082(0.125)$ & $0.110(0.051)$ & $0.446(0.176)$ & $0.398(0.140)$ \\
\hline
\end{tabular}

$a O R$ odds ratio adjusted simultaneous to the other individual characteristics; NA Not available;

${ }^{a}$ Women stopped work $\leq 3$ months of pregnancy

${ }^{\mathrm{b}}$ Standard Error

'There were only few women having 3 or more children in 2009; thus the odds ratio was not calculated

${ }^{\mathrm{d} S}$ Statistical significant figures $\mathrm{d}$ are marked in bold

woman and her husband. Occupational health and safety in China has improved in the last few years [26], but is not likely to have affected the majority of our study population, who were self-employed farmers.

In China there are many traditional pregnancy and birth practices such as restrictions on diet or activity during pregnancy [27-30], and these vary locally [31, 32]. In traditional Chinese medicine it is believed that maintaining emotional harmony is important because anything that influences a women's mind or spirit, e.g. too much joy and strenuous physical work, affect the heart and can affect the fetus [33]. However, changes 
in cultural beliefs are unlikely in such a short time period.

In Chinese prenatal care, various behavioral changes and restrictions are recommended to the mother to protect the unborn child [28]. However, there are no recommendations as regards stopping work early in pregnancy. Women are advised to avoid various activities such as carrying heavy loads or engaging in strenuous work during the first trimester, but there is no advice to stop work completely in the first trimester. In 2001-03 women starting their prenatal care visits late (at 7-9 months of pregnancy) were more likely to stop working early in pregnancy; in 2009 the time of starting prenatal care was not associated with stopping work early. This does not suggest that advice from health care was the cause.

The rules of population policy (one child policy) could have contributed to stopping working. In our study area (Anhui Province), a second child was allowed if the first birth was a daughter [34]. With one or two children allowed, the pregnancy and the future health of the child becomes very important.

The average income increased considerably during the study period. We do not have information on the maternity allowance system or whether women received any compensation if they did not work during pregnancy. However, this was unlikely for farmers, who are selfemployed. We think that the most likely reason for the rapid increase in stopping work in early pregnancy was the traditional beliefs about the harmfulness of strenuous physical exercise, the increased value of pregnancy, and the increased wealth making stopping work possible.

\section{Strengths and limitations}

The most important limitation was that the two surveys were done in different counties, even though in the same province. We cannot exclude the possibility, however remote, that the counties were different in respect to working behavior during pregnancy. The surveys had different response rates, but the difference in work behavior was so great that it is unlikely that it could be explained by response rate. We did not have detailed information on the content of these women's work. However, working the same as before until the end of pregnancy may have meant heavy labor, as most of the women were farmers. Another drawback was that we do not have information on the work content, but only the rough classification into farmers and others. There may have been recall bias in retrospectively assessing women's patterns of work and start of prenatal care. The women's income was selfreported, and we do not know how accurate it was.

\section{Conclusions}

Further research is needed on how pregnant women work, by occupation and type of work, and whether work patterns are related to pregnancy outcomes. Country comparisons would be useful to identify local peculiarities.

\section{Abbreviations \\ aOR, adjusted odds ratio; CHIMACA, Structural hinders to and Promoters of Good Maternal Care in Rural China; Cl, Confidence Intervals; CNY, Chinese Yuan; ICRH, International Center for reproductive Health; KAP, Knowledge, Attitude and Practice}

\section{Acknowledgements}

The authors thank all the women who participated in the surveys and the local researchers who collected the data.

\section{Funding}

The second survey of this study is part of the result of the CHIMACA project (015396) funded by the European Commission INCO program and coordinated by the National Institute for Health and Welfare, Helsinki. The researchers are independent from funder.

\section{Availability of data and materials}

The data of the second survey has been archived and available for analysis through Finnish Social Science Data Archive (www.fsd.uta.fi/en). The data of the first survey were not shared in order to protect the participants' identity.

\section{Authors' contributions}

SN conceptualized the study, carried out the statistical analysis and drafted the manuscript. EH designed and participated in the whole project. BIN, ZW, and $\mathrm{EH}$ critically revised the manuscript. The final version of the manuscript was read and approved for submission to the journal by all authors.

\section{Competing interests}

The authors declare that they have no competing interests.

Consent for publication

Not applicable.

\section{Ethics approval and consent to participate}

Ethical approval for the first study was obtained from the ethics committee of the National Institute for Health and Welfare (formerly the National Research and Development Centre for Welfare and Health) in Helsinki, Finland. The second study was granted ethical approval by the International Center for reproductive Health (ICRH), Ghent University, Belgium. Local approvals were obtained from Anhui Medical University. Informed oral consent was obtained from each woman in both surveys before the interview.

\section{Author details}

${ }^{1}$ School of Health Sciences, Fl-33014 UNiversity of Tampere, Tampere, Finland. ${ }^{2}$ Centre for Medical Informatics, Usher Institute of Population Health Sciences and Informatics, The University of Edinburgh, Edinburgh, UK. ${ }^{3}$ School of Public Health, Fudan University, Shanghai, China. ${ }^{4}$ National Institute for Health and Welfare, Helsinki, Finland.

Received: 4 September 2015 Accepted: 17 June 2016

Published online: 08 July 2016

\section{References}

1. Marbury MC, Linn S, Monson RR, et al. Work and Pregnancy. J Occup Med. 1984;26:415-21.

2. International Labor Organization (ILO). Safe maternity and the world of work, 2007; ISBN 978-92-2-120404-6 (Web pdf).

3. Graner S, Klingberg-Allvin M, Phuc HD, Huong DL, Krantz G, Mogren I. Adverse perinatal and neonatal outcomes and their determinants in rural Vietnam 1999-2005. Pediatr Perinat Epidemiol. 2010;24:535-45.

4. Niedhammer I, O'Mahony D, Daly S, Morrison JJ, Kelleher CC. Occupational predictors of pregnancy outcomes in Irish working women in the Lifeways cohort. BJOG. 2009;116:943-52.

5. Mutambudzi M, Meyer JD, Warren N, Reisine S. Effects of Psychosocial Characteristics of Work on Pregnancy Outcomes: A Critical Review. Women Health. 2011;51(3):279-97. 
6. Bonzini M, Palmer K, Coggon D, Carugno M, Cromi A, Ferrario M. Shift work and pregnancy outcomes: a systematic review with meta-analysis of currently available epidemiological studies. BJOG. 2011;118(2):1429-37.

7. Bell JF, Zimmerman FJ, Diehr PK. Maternal work and birth disparities. Matern Child Health J. 2008;12:415-26.

8. Simcox AA, Jaakkola JJ. Does work as a nurse increase the risk of adverse pregnancy outcomes? J Occup Environ Med. 2008;50:590-2.

9. Li X, Sundquist J, Sundquist K. Parental occupation and risk of small-forgestational-age births: a nationwide epidemiological study in Sweden. Hum Reprod. 2010;25:1044-50.

10. Ahmed $\mathrm{P}$, Jaakkola JJ. Maternal occupation and adverse pregnancy outcomes: a Finnish population-based study. Occup Med (Lond). 2007;57:417-23.

11. Omokhodion FO, Onadeko MO, Roberts OA, Beach JR, Burstyn I, Cherry NM. Paid work, domestic work, and other determinants of pregnancy outcome in Ibadan, Southwest Nigeria. Int J Gynecol Obstet. 2010;111:165-70.

12. Charmberlain G. Pregnant women at work. London: Royal Society of Medicine and Macmillan Press; 1984.

13. Neupane S, Nwaru BI, Zhuochun W, Hemminki E. Work behaviour during pregnancy in rural China in 2009. Eur J Public Health. 2014;24(1):170-5.

14. Jacka T. Women's work in rural China: change and continuity in an era of reform. Hong Kong: Cambridge University Press; 1997.

15. Wu Z, Viisainen K, Li X, Hemminki E. Maternal care in rural China: a case study from Anhui Province. BMC Health Serv Res. 2008:8:55-63.

16. Long Q, Klemetti R, Wang Y, Tao F, Yan H, Hemminki E. High caesarean section rate in rural China: Is it related to health insurance (New co-operative medical scheme)? Soci Sci Med. 2012;75:733-7.

17. Nwaru $\mathrm{Bl}, \mathrm{Wu} \mathrm{Z}$, Hemminki E. Infant care practices in rural China and their relation to prenatal care utilization. Global Public Health. 2011;6:1-14.

18. Klemetti R, Regushevkaya E, Zhang WH, Raven J, Long Q, Huang Kun et al. New mothers' survey in 2008 in rural China: CHIMACA report. Report 23, 2010. Helsinki, Finland: National Institute for Health and welfare

19. Zhang WH, Raven J, Zhang T, Shen Y, Huang K, Long Q et al. Implementation of interventions in the CHIMACA project. Discussion paper 13, 2010. Helsinki, Finland: National Institute for Health and Welfare

20. Nwaru Bl, Klemetti R, Yuan S, Kun H, Wang Y, Hemminki E. Completeness and utility of interview data from proxy respondents in prenatal care research in rural China. Matern Child Health J. 2012;16:867-76.

21. Stephenson R. Community influences on young people's sexual behavior in three African countries. Am J Public Health. 2009;99(1):102-9.

22. American Academy of Pediatrics (AAP) \& American College of Obstetricians and Gynecologists (ACOG). Guidelines for perinatal care ( $7^{\text {th }}$ ed.). ELK Grove Village, (IL): AAP; Washington, DC: American College of Obstetricians and Gynecologists; 2102. p. 109-110, 160, 192-194, 248.

23. Gerhardsson L, Lillienberg L. Working and environmental risks during pregnancy: guidelines for assessment occupational and environmental medicine. Gothenburg, Sweden: The Sahlgrenska University Hospital; 2009

24. Hemminki E, Wu Z, Cao G, Viisainen K. Illegal births and legal abortions the case of China. Reprod Health. 2005;2:5.

25. Devine C, Bove C, Olson C. Continuity and change in women's weight orientations and lifestyle practices through pregnancy and the postpartum period: the influence of life course trajectories and transitional events. Soc Sci Med. 2000;50:567-82

26. National profile report on occupational safety and health in China. ILO report, 2012 available online: http://www.ilo.org/wcmsp5/groups/public/ed_protect/_protrav/—safework/documents/policy/wcms_186991.pdf

27. Lee DT, Ngai IS, NG MM, Lok IH, Yip AS, Chung TK. Antenatal taboos among Chinese women in Hong Kong. Midwifery. 2009:25:104-13.

28. Lau Y. Traditional Chinese pregnancy restrictions, health-related quality of life and perceived stress among pregnant women in Macao, China. Asian Nurs Res. 2012;6:27-34

29. Liamputtong P, Yimyam S, Parisunyakul S, Baosoung C, Sansiriphun N. Traditinal beliefs about pregnancy and childbirth among women from Chiang Mai, North Thailand. Midwifery. 2005;21:139-53.

30. Kaaya SF, Mbwambo JK, Fawzi MCS, Borne HVD, Schaalma H, Leshabari MT. Understanding women's experiences of distress during pregnancy in Dar es Salaam, Tanzania. Tanzan J Health Res. 2010;12:1-12.

31. Aayaz S, Efe SY. Potentially harmful traditional practices during pregnancy and postpartum. Eur J Contracept Reprod Health Care. 2008;13:282-8.

32. Manyande A, Grabowska C. Factors affecting the success of moxibustion in the management of a breech presentation as a preliminary treatment of external cephalic version. Midwifery. 2009;25:774-80.
33. Xuan W. Traditional Chinese medicine. In: Yuan CS, Bieber EJ, Bauer BA, editors. Textbook of complementary and alternative medicine. 2nd ed. London: Informa Healthcare; 2006.

34. Hemminki $\mathrm{E}$, Long Q, Wu Z, Klemetti R. Impact of Chinese one-child policy on sibling structure: experience from rural areas in three provinces. BMJ Open. 2012;2:e001010

\section{Submit your next manuscript to BioMed Central and we will help you at every step:}

- We accept pre-submission inquiries

- Our selector tool helps you to find the most relevant journal

- We provide round the clock customer support

- Convenient online submission

- Thorough peer review

- Inclusion in PubMed and all major indexing services

- Maximum visibility for your research

Submit your manuscript at www.biomedcentral.com/submit
C Biomed Central 